\title{
Indian Rural Market: An Impulse to FMCG Sector
}

\author{
Avinash Pareek ${ }^{1}$, Dr. Satyam Pincha ${ }^{2}$ \\ ${ }^{I}$ (Department of Management, IASE Deemed University, Sardarshahr, India) \\ ${ }_{2}^{2}$ (Department of Management, IASE Deemed University, Sardarshahr, India)
}

\begin{abstract}
The Fast Moving Consumer Goods (FMCG) sector is a foundation stone of the growing Indian economy. This sector strikes every facet of human life. The FMCG producers now realize that there is a lot of prospect for them to enter into the rural market. The rising incomes and growing lifestyle is a significant attraction for this sector. There are more than middle income households in the rural areas as compare to the urban. Thus the rural marketing has been growing progressively over the years and is now bigger than the urban market. Globally, the FMCG sector has been successful in selling products to the lower and middle income groups in India. More than $70 \%$ of sales are made to middle class households today and over $50 \%$ of the middle class residing in rural India. The FMCG sector is energized about a rapidly increasing rural population whose incomes are intensifying and which is willing to spend on goods designed to improve their lifestyles. Also with a near saturation and cut throat competition in urban India, many manufacturers and marketers of this sector are driven to formulate new strategies for targeting the rural consumers. But the rural penetration rates are low. This presents a tremendous opportunity for manufacturers of branded products who can convert prospective consumers into consumers to buy their products. Companies including Multi National Companies and regional players started developing marketing strategies to attract this untouched market. While formulating the strategies, the marketers need to take care of the rural consumers differently from urban consumers because they are economically, socially and psycho-graphically different from each other.
\end{abstract}

Key Words: Fast Moving Consumer Goods, Rural consumer, Marketing Strategy, Urban consumers, Indian Economy

\section{Introduction}

Rural India is a powerhouse propelling the economy's growth. Home to two-thirds of the country's one billion consumers, it is the zone where almost half of the national income is generated. Marketers are focussing on the Indian hinterlands to achieve their revenue targets by increasing their presence into the rural markets. Marketers are looking the aspiring rural and semi-urban India to yoke growth opportunities. Cable and satellite penetration has helped in a big way to access hard-to-reach rural areas. Moreover, advertising budgets for rural markets do not demand much of the liquidity. Marketing of products and services through simple ways like village melas (fairs), nukkad natikas (road theatre), boat branding, mobile vans and wall paintings prove to be very effective and that too at minimal costs.

Both FMCG companies and automobile companies are the biggest advertisers in semi-urban and rural markets. Most of the FMCG firms follow the strategy of coming up with small size packs for the people residing in remote areas. Euromonitor International's survey has found that 68 per cent of personal care products were sold in rural India in FY 12 as against 31 per cent in cities. Thus, markets in rural and semi-urban India are on the edge to be the future growth drivers due to higher disposable incomes, rising desires of people to own quality products and improved infrastructure support extended by the Government for the development of these areas.

The Indian Fast Moving Consumer Goods (FMCG) industry began to shape during the last fifty odd years. The FMCG sector is a foundation stone of the Indian economy. This sector touches every aspect of human life. Indian FMCG market can be divided between the organized sector and the unorganized sector. Unlike the US market for FMCG which is dominated by global players, India's FMCG market remains highly fragmented with roughly half of the market going to unbranded, unpackaged and home made products. This presents a tremendous opportunity for manufacturers and marketers of branded products who can convert consumers to buy their products.

Around the Globe, the FMCG sector has been successful in selling products to the lower and middle income groups, and the same scenario is true for Indian markets. Around more than $70 \%$ of sales are made to middle class households today and out of which more than $50 \%$ is in rural India. The sector is excited about a rapidly increasing rural population whose incomes are rising and which is willing to spend on goods designed to improve lifestyle. Also with a near saturation and cut throat competition in urban India, many manufacturers of FMCGs are driven to formulate new strategies for targeting the rural consumer. MART, the specialist rural marketing and rural development consultancy, has found that 53 per cent of FMCG sales and 59 per cent of 
consumer durable sales lie in the rural areas. According to a study by Chennai-based Francis Kanoi Marketing Planning Services Pvt Ltd, the rural market for FMCG is worth Rs.65,000 crore, for durables Rs 5000 crore, for tractors and agri-inputs Rs.45,000 crore and two- and four-wheelers, Rs.8000 crore. In total, a whopping Rs.123,000 crore. This could be doubled if corporate understood the rural buying behaviour and got their distribution and pricing right.

\subsection{Hypotheses}

Researcher envisions Marketing Strategy for unexplored rural markets.

\subsection{Methodology}

The method of study is descriptive. The study surveys from Internet, textbooks, reports, journals and from selfknowledge.

\subsection{Importance of the Study}

This study covers the attractions for the FMCG marketers to go to rural, and the suitable marketing strategy with the suitable example of companies and their experience in going rural.

\subsection{Objectives}

1.4.1 To understand the meaning of rural market

1.4.2 To find the way's how rural market can be explored

1.4.3 To understand the use of marketing strategy for rural market as separate from urban

What makes Rural Markets Attractive?

\section{Results \& Discussion}

The Indian rural market with its vast size and demand, offers great opportunities to manufactures and marketers. Two-thirds of total consumers of country live in rural areas and almost half of the national income is generated from rural and semi-urban areas. It is natural that rural markets shape an important part of the total market of India. Our nation is classified in approximately 6,30,000 villages, which can be sorted in different parameters such as literacy levels, income levels, penetration, distances etc. Rural market has the following facts substantiate this.

- 742 million people

- Estimated annual size of the rural market

- FMCG Rs. 65,000 Crore

- Durables Rs. 5,000 Crore

- Agri-inputs (incl. tractors) Rs 45,000 Crore

- $2 / 4$ wheelers Rs. 8,000 Crore

- In 2001-02, LIC sold $55 \%$ of its policies in rural India.

- Of two million BSNL mobile connections, 50\% in small towns/villages.

- Of the six lakh villages, 5.22 lakh have a Village Public Telephone (VPT)

- 41 million Kisan Credit Cards issued (against 22 million credit-plus-debit cards in urban) with cumulative credit of Rs 977 billion resulting in tremendous liquidity.

- Of 20 million Rediffmail signups, $60 \%$ are from small towns. 50\% transactions from these towns on Rediff online shopping site

- Investment in formal savings instruments: 6.6 million HHs in rural and 6.7 million in urban.

Features of Indian Rural Markets

- Large and Scattered market: The rural market of India is large and scattered in the sense that it consists of over 74 crores consumers from 6,30,000 villages spread throughout the country.

- Major income from agriculture: Nearly $60 \%$ of the rural income is from agriculture. Hence rural prosperity is tied with agricultural prosperity.

- Traditional Outlook: The rural consumer values old customs and tradition. They do not prefer changes.

- Diverse socio-economic backwardness: Rural consumers have diverse socio-economic backwardness. This is different in different parts of the country.

- Infrastructure Facilities: The Infrastructure Facilities like roads, warehouses, communication system, and financial facilities are inadequate in rural areas. Hence physical distribution becomes costly due to inadequate Infrastructure facilities. The rural bazaar is booming beyond everyone's expectation. 


\subsection{Impulse to go Rural}

Indian rural markets are poised to grow ten-fold by 2025 to become a US\$ 100 billion proposition for retailer, according to the Chairman of HUL. A report by Boston Consulting Group (BCG) and CII projects that small town and rural customers would be the single largest market segment constituting 36 per cent of households by 2020, while rural and urban aspirers will make up the next largest category at 23 per cent of all households.

There are many reasons that have urged the FMCG companies to enter the uncharted territory of rural India. Some of the attractions are discussed below.

\subsubsection{Population}

The rural Indian population is large and its growth rate is also high. Over 70\% India's one billion plus population lives in around 6,30,000 villages in rural areas. This simply shows the great potentiality to marketers.

TABLE-1: Percentage Distribution of Households and Income

\begin{tabular}{|l|l|l|}
\hline Area & Households & Population \\
\hline Rural & 72.6 & 74.6 \\
\hline Urban & 27.4 & 25.4 \\
\hline All-India & 100 & 100 \\
\hline
\end{tabular}

\subsubsection{Growing Rural Prosperity}

India is now seeing a dramatic shift towards prosperity in rural households. To drive home the potential of rural India just consider some of these impressive facts about the rural sector. As per the National Council for Applied Economic Research (NCAER) study, there are as many 'middle income and above' households in the rural areas as there are in the urban areas.

This apparently is the result of development work, which happened under the five years plans and other special programmes such as land reforms, rural electrification rural communication, and rural credit facilities, etc. The absolute size of the rural market is thus expected to double that of urban India. But despite the high rural share in these categories, the rural penetration rates are low, thus offering tremendous potential for growth. As a result of the growing affluence, fuelled by good monsoons and the increase in agricultural output to 200 million tonnes from 176 million tonnes in 1991, rural India has a large consuming class with 41 per cent of India's middle-class and 58 per cent of the total disposable income.

\subsubsection{Growth in Market}

The importance of the rural market for some FMCG and durable marketers is underlined by the fact that the rural market accounts for close to 70 per cent of toilet-soap users and 38 per cent of all two-wheeler purchased. The rural market accounts for half the total market for TV sets, fans, pressure cookers, bicycles, washing soap, blades, tea, salt and toothpowder, What is more, the rural market for FMCG products is growing much faster than the urban counterpart.

The purchasing power in rural India is on steady rise and it has resulted in the growth of the rural market. The market has been growing at 3-4\% per annum adding more than one million new consumers every year and now accounts for close to 50\% of volume consumption of FMCG. The growth rates of lot of FMCG are higher in rural markets than urban markets.

\subsubsection{Effectiveness of Media Communication}

Effective communication is an important tool to reach the rural audience. Among the mass media at some point of time in the late 50's and 60's radio was considered to be a potential medium for communication to the rural people. Another mass media is television and cinemas. But now a day the scenario has changed. Television, telephone, mobile, internet etc. reached to every house in the rural India. So communication through these has become more easy and better to the remote areas. A rural consumer is brand loyal and understands symbols better. Television has been a major effective communication system for rural mass and, as a result, companies should identify themselves with their advertisements. Advertisements touching the emotions of the rural folks, it is argued, could drive a quantum jump in sales.

Mass media is able to reach only to $57 \%$ of the rural population. Creating awareness then, means utilizing targeted, unconventional media including ambient media .For generating awareness, events like fairs and festivals, Haats, etc., are used as occasions for brand communication. Cinema vans, shop-fronts, walls and wells are other media vehicles that have been utilized to increase brand and pack visibility. Innovative media used by personal wash like Lux and Lifebuoy and fabric wash items like Rin and Wheel. Idea was to advertise not only at the point of purchase but also at the time of consumption. 
With large parts of rural India inaccessible to conventional advertising media - only 41 per cent rural households have access to TV - building awareness is another challenge. However, the rural consumer expressions differ from his urban counterpart. Outing for the former is confined to local fairs and festivals and TV viewing is confined to the state-owned channels. Consumption of branded products is treated as a special treat or indulgence.

Hindustan Lever relies heavily on its own company-organised media. These are promotional events organised by stockists. Godrej Consumer Products, which is trying to push its soap brands into the interior areas, uses radio to reach the local people in their language. Coca-Cola uses a combination of TV, cinema and radio to reach 53.6 per cent of rural households. Since price is a key issue in the rural areas, Coca-Cola advertising stressed its 'magical' price point of Rs 5 per bottle in all media.LG Electronics uses vans and road shows to reach rural customers. The company uses local language advertising. The key dilemma for MNCs eager to tap the large and fast-growing rural market is whether they can do so without hurting the company's profit margins. In case of nestle, company's product portfolio is essentially designed for urban consumers which cautions companies from plunging headlong into the rural market as capturing rural consumers can be expensive.

\subsubsection{IT infiltration in Rural India}

Around fifteen to twenty years back, history was created with Public Call Office phone booths (essentially manually operated payphone facilities), opening in every corner of the country. This experiment was an instant success and contributed to hundreds of thousands of jobs. The rural consumers spend time and money to access higher level information. Studies have indicated that if the content has direct relevance and will result in commercial gains, people in rural areas are willing to pay for information services. Consumerism has altered rural buying behaviour in recent years. Spending patterns of those who spend are now adapting to face the technology bug. Today's rural children and youth will grow up in an environment where they have 'information access' to education opportunities, exam results, career counselling, job opportunities, government schemes and services, health and legal advice and services, worldwide news and information, land records, mandi prices, weather forecasts, bank loans, livelihood options. If television could change the language of brand communication in rural India, affordable Web connectivity through various types of communication hubs will surely impact the currency of information exchange. As the electronic ethos and IT culture moves into rural India, the possibilities of change are becoming visible.

\subsubsection{Impact of Globalization}

The impact of globalization is felt in rural India as much as in urban. But it is slow. It has its impact on target groups like farmers, youth and women. Farmers, today 'keep in touch' with the latest information and maximize both ends. Animal feed producers no longer look at Andhra Pradesh or Karnataka. They keep their cell phones constantly connected to global markets. Surely, price movements and products' availability in the international market place seem to drive their local business strategies. On youth its impact is on knowledge and information and while on women it still depends on the socio-economic aspect. The marketers who understand the rural consumer and fine tune their strategy are sure to reap benefits in the coming years. In fact, the leadership in any product or service is linked to leadership in the rural India except for few lifestyle-based products, which depend on urban India mainly.

Foreign Direct Investment has become an integral part of national development strategies globally. The trend in FDI inflows reflects growing investor interest in Indian economy on the back of strong fundamentals and simplified business procedures. This needs to be given further push and guided in the right direction. There are ample opportunities for the growth and inflows of FDI into rural India, which could address the structural imbalance of Indian economy and will help improving the lot of bottom section.

\subsubsection{Government Initiatives for Rural Development}

Government of India has been very proactive to give maximum space for growth to rural areas. Supportive programs like National Rural Employment Guarantee Scheme, minimum support prices for farm produce and other incentives have boosted rural incomes which has facilitated better standard of living for these masses. Moreover, the proposal to increment budget allocation from Rs 10,000 crore (US\$ 1.8 billion) to Rs 58,000 crore (US\$ 10.4 billion) would give an impetus to rural awakening and growth.

Meanwhile, the Government of India has pledged to enhance the reach of National Rural Health Mission (NHRM) to all villages and towns. It would be implementing a new scheme under which free medicines through public hospitals and health centres would be distributed among the rural Indians.

\subsection{Some Live Examples of Companies experiences in going Rural:}

- One very fine example can be quoted of Escorts where they focused on deeper penetration. They did not rely on T.V. or press advertisements rather concentrated on focused approach depending on geographical 
and market parameters like fares, melas etc. Looking at the 'kuchha' roads of village they positioned their bike as tough vehicle. Their advertisements showed Dharmendra riding Escort with the punch line 'Jandar Sawari, Shandar Sawari'. Thus, they achieved whopping sales of 95000 vehicles annually.

- HUL started 'Operation Bharat' to tap the rural markets. Under this operation it passed out low-priced sample packets of its toothpaste, fairness cream, Clinic plus shampoo, and Ponds cream to twenty million households.

- ITC is setting up e-Choupals which offers the farmers all the information, products and services they need to enhance farm productivity, improve farm-gate price realization and cut transaction costs. Farmers can access latest local and global information on weather, scientific farming practices as well as market prices at the village itself through this web portal - all in Hindi. It also facilitates supply of high quality farm inputs as well as purchase of commodities at their doorstep.

- BPCL Introduced Rural Marketing Vehicle (RMV) as their strategy for rural marketing. It moves from village to village and fills cylinders on the spot for the rural customers. BPCL considered low-income of rural population and therefore introduced a smaller size cylinder to reduce both the initial deposit cost as well as the recurring refill cost.

\subsection{Some Live Examples of Companies Investments and Developments in Rural:}

- IFFCO Kissan Sanchar Limited (IKSL) has conceptualised green SIM Card for rural community groups wherein the subscribers receive five free voice messages every day, covering diverse areas from best farm practices to availability of fertiliser and pesticides, market price of agri-commodities, Government schemes and so on. IKSL has divided 18 states into 53 agro-climatic zones and has made its service available in 18 languages. India rural landscape has been transformed in a way through this mobile voice message service.

- Consumer durables company Philips has decided to develop healthcare products exclusively for rural markets in India. The company's healthcare division is focussing its efforts on developing low-cost products and reasonably priced solutions in cardiology, cervical cancer and mother and child-care segments for rural India.

- Continuing with its investments to expand its reach in rural areas, Emami, half of whose revenues are generated from rural India only, has widened its distribution network from 0.5 million outlets in March 2012 to 0.6 million outlets, according to a report from Edelweiss Institutional Equities.

- India's second largest mobile phone company by value and the fastest growing wireless-phone company, Idea Cellular Ltd is targeting rural customers to sustain its 25 per cent growth in revenue. The company expects maximum push from new subscribers in small towns and villages who are also increasing their data usage by upgrading to smart-phones.

- Rural India is also witnessing a transformation when it comes to telecom. The second phase of telecom revolution aims to build broadband networks that would connect almost 2,50,000 panchayats through optical fibre. Meanwhile, operators will enhance the usage of voice platform along with the localised content to ensure widespread adoption in rural zones, according to Media and Telecommunications (TMT) predictions India 2012 report by Deloitte.

\section{Developing Effective Rural Marketing Strategy}

'Go rural' is the slogan of marketing gurus after analyzing the socio-economic changes in villages. The success of a brand in the Indian rural market is as unpredictable as rain. It has always been difficult to determine the rural market. Many brands, which should have been successful, have failed miserably. Usually, people attribute rural market success to luck. Therefore, marketers need to understand the social dynamics and attitude variations within each village though nationally it follows a consistent pattern looking at the challenges and the opportunities which rural markets offer to the marketers it can be said that the future is very promising for those who can understand the dynamics of rural markets and exploit them to their best advantage. A radical change in attitudes of marketers towards the vibrant and burgeoning rural markets is called for, so they can successfully impress on the millions of rural consumers spread over approximately 6,30,000 villages in rural India.

\subsection{What rural market buys?}

Rural India buys small packs, as they are perceived as value for money. There is brand stickiness, where a consumer buys a brand out of habit and not really by choice. Brands rarely fight for market share; they just have to be visible in the right place. Even expensive brands, such as Close-Up, Marie biscuits and Clinic shampoo are doing well because of deep distribution, many brands are doing well without much advertising support - Ghadi, a big detergent brand in North India, is an example. 


\subsection{Why Rural Market?}

The Indian rural market has a huge demand base and offers great opportunities to marketers. Twothirds of Indian consumers live in rural areas and almost half of the national income is generated here. The reasons for heading into the rural areas are fairly clear. The urban consumer durable market for products like colour TVs, washing machines, refrigerators and air conditioners is growing annually at between 7 per cent and 10 per cent.

The rural market is zooming ahead at around 25 per cent annually. "The rural market is growing faster than urban India now," says Venugopal Dhoot, chairman of the Rs 989 -crore(Rs billion) Videocon Appliances. "The urban market is a replacement and up gradation market today," adds Samsung's director, marketing, Ravinder Zutshi.

Most of the FMCG companies used to treat rural markets as adjuncts to their urban Strong holds and rural consumers as a homogeneous mass without segmenting them into target markets and positioning brands appropriately. The winning strategy instead is to focus on their core competency such as technological expertise to design specific products for the rural economy. The most remarkable example in this context is the launch of sachets which has transformed the rural market considerably as packaging in smaller units and lesser-priced packs increases the product's affordability. Also companies like HUL and Nestle who have adopted this strategy have benefited tremendously. Another case is of Britannia with its Tiger brand of low priced and conveniently packaged biscuits becoming a great success story in rural markets.

Companies also need to change the profile of their brand managers. A step in this direction like hiring managers from the Institutes of Rural Management could probably go a long way in improving the situation. Along with the cultural dynamics, the needs and latent feelings of the rural people have to be well understood before launching products in rural segments. Marketers would do well to first understand this and then designing products accordingly. For example, Chick shampoo has launched in small sachets, which is based on the consumer insight that rural consumers opt for this rather than costlier toiletries.

Another very important factor that needs to be looked at is the proliferation of spurious products. Rural masses are illiterate people and they identify a product by its packaging (colour, visuals, size etc.). So it becomes very easy for counterfeit products to eat into the market share of established reputed brands. The retailer also gets a larger profit on selling the counterfeits rather than the genuine products and hence is biased towards the fakes. Brands such as "Jifeboy", "Bonds Talcum", "Funny \& Lovely" etc., which are doing the rounds of rural markets, pose considerable challenge to rural marketers.

Companies would also do well to have a proper sales and distribution network. In terms of sheer reach the companies can gain significant competitive advantages as the rural market is highly fragmented and a brand needs to be on the shop shelf before it can be sold. Companies should also make sure that the prices of their products are not pushed up because of a channel of middlemen who are neither required nor add any value to the product. The rural market remains quite price-sensitive and thus squeezing costs at every stage is of vital importance. Some FMCG giants like HLL are in process of enhancing their control on the rural supply chain through a network of rural sub-stockists, who are based in the villages only. Apart from this to acquire further edge in distribution HLL has started Project Shakti in partnership with Self Help groups of rural women. However not all traditional strategies need to work and the need is to generate creative ideas. A very significant step for change could be an effort to directly tap the haats, mandis, melas and local bazaars which provide an opportunity of promoting the brand in front of a large congregation of rural consumers.

Finally an effective rural strategy for FMCG companies must include the use of traditional media for creating awareness about their products in the rural markets. The need for unconventional media arises as the mass media is too glamorous, interpersonal and unreliable for a rural consumer. The traditional media on the other hand with its effective reach, powerful input and personalized communication system will help in realizing the goal. Besides this when the advertisement is couched in entertainment it goes down easily with the villager. The advantages of traditional media which make it a powerful marketing communication channel are: accessibility is high, it involves more then one sense, interest arousal capability is high and minimum cost. There are few companies which have used traditional media effectively and reaped rich dividends. Brooke Bond Lipton India Ltd (BBLIL) markets its rural brands through magic shows and skits. Reckitt and Colemen uses NGO's in rural areas to educate customers about product benefits which establishes one to one communication channels.

\section{Conclusions}

In the end it is certain that FMCG companies will have to really gain inroads in the rural markets in order to achieve double digit growth targets in future. There is huge potential and definitely there is lot of money in rural India but the smart thing would be to weigh in the roadblocks as carefully as possible. The companies entering rural market must do so for strategic reasons and not for tactical gains as rural consumer is still a closed book and it is only through unwavering commitment that the companies can make a dent in the 
market. Ultimately the winner would be the one with the required resources like time and money and also with the much needed innovative ideas to tap the rural markets. Thus looking at the opportunities which rural markets offer to the marketers it can be said that the future is very promising for those who can understand the dynamics of rural markets and exploit them to their best advantage. A radical change in attitudes of marketers towards the vibrant and burgeoning rural markets is called for, so they can successfully impress on the millions of rural consumers spread over approximately 6,30,000 villages in rural India.

\section{References:}

[1] V. Badi Ravindranath and V. Badi Naranyansa, Rural Marketing (New Delhi: Himalaya Publishing, 2004),

[2] Ruchika Ramakrishnan, Rural Marketing in India: Strategies and Challenges (New Delhi: New Century Publications, 2006)

[3] Philip Kotler, "Marketing Management" (New Delhi: Pearson Education Pvt. Ltd., 2003)

[4] Dogra, Rural Marketing (New Delhi:Tata McGraw-Hill Education, 2007)

[5] Krishnamachary, Rural Marketing: Text \& Cases (New Delhi: Pearson Education India, 2011)

[6] Rajendhiran N., Saiganesh S., Rural Marketing - A Critical Review, viewed on Aug. 10, 2012 (http://www.indianmba.com/Faculty_Column/ FC658/fc658.html)

[7] General Overview, "Rural market" (http://india.gov.in/sectors/rural/index.php?id=2)

[8] "Rural market" http://www.ibef.org/industry/consumermarket/ruralmarket.aspx

[9] The Hindu - Business Line

[10] www.deccanherald.com 